\title{
Room Temperature Superconductivity
}

Published online: 7 January 2021

(C) Springer Science+Business Media, LLC, part of Springer Nature 2021

Dream about room temperature superconductivity (RTS) was envisioned shortly after the discovery made by H. KamerlinghOnnes in 1911. The first observation of RTS's phenomenon was recently carried out and described in the paper "Room-temperature superconductivity in a carbonaceous sulfur hydride" by E. Snider, N. Dasenbrock-Gammon, R. McBride, M. Debessal, H. Vindana, K. Cantasamy, K. Lawler, A. Salamat, and R. Dias (Nature, 586, 373 (2020)).

More specifically, the material is in the superconducting state up to the temperature $\mathrm{Tc}=288 \mathrm{~K}$ (near $15^{\circ} \mathrm{C}$ ). The effect has been observed at high pressure $P=267 \pm 10 \mathrm{GPa}$ (let us remind that $\left.1 \mathrm{GPa}=10^{4} \mathrm{~atm}\right)$. The structural unit contains $\mathrm{H}_{2} \mathrm{~S}+\mathrm{H}_{2}+\mathrm{CH}_{4}$ sub-units. Interestingly, the two first components form under pressure the hydride $\mathrm{SH}_{3}$, the first high Tc hydride. The ideal stoichiometry, probably, is $\left(\mathrm{H}_{2} \mathrm{~S}\right)\left(\mathrm{CH}_{4}\right) \mathrm{H}_{2}$.
The sub-units are bound by the van der Waals forces. Note that the unit's structure is unknown, and its evaluation is a non-trivial problem since the usual method, X-ray spectroscopy, is not efficient in this case because of light masses of hydrogen and carbon.

The superconducting state is manifested in a drastic drop of resistivity, a decrease in Tc with an increase in an external magnetic field, and the Meissner effect. The last factor is the crucial one since the Meissner effect is the direct evidence of the superconductivity.

The search for materials, which display RTS at a lower pressure (the goal: ambient pressure), is the next important challenge.

Vladimir Kresin

Publisher's note Springer Nature remains neutral with regard to jurisdictional claims in published maps and institutional affiliations. 